\title{
Mature salivary gland rests within sonic hedgehog-positive medulloblastoma: case report and insights into the molecular genetics and embryopathology of ectopic intracranial salivary gland analogs
}

\author{
Berje Shammassian, MD, ${ }^{1}$ Sunil Manjila, MD, ${ }^{1}$ Efrem Cox, MD, ${ }^{1}$ Kaine Onwuzulike, MD, PhD, ${ }^{1}$ \\ Dehua Wang, MD, ${ }^{4}$ Mark Rodgers, MD, ${ }^{3}$ Duncan Stearns, MD, ${ }^{2}$ and Warren R. Selman, MD ${ }^{1}$ \\ 1Department of Neurological Surgery, The Neurological Institute, and '3epartment of Pathology, University Hospitals Case \\ Medical Center, Cleveland; 'Division of Pediatric Neuro-Oncology, Department of Pediatrics, Rainbow Babies and Children's \\ Hospital, University Hospitals Case Medical Center, Cleveland; and ${ }^{2}$ Department of Pathology, University of Cincinnati, \\ Cincinnati Children's Hospital Medical Center, Cincinnati, Ohio
}

\begin{abstract}
Intracranial ectopic salivary gland rests within dural-based lesions are reported very infrequently in the literature. The authors report the unique case of a 12-year-old boy with a cerebellar medulloblastoma positive for sonic hedgehog (Shh) that contained intraaxial mature ectopic salivary gland rests. The patient underwent clinical and radiological monitoring postoperatively, until he died of disseminated disease. An autopsy showed no evidence of salivary glands within disseminated lesions. The intraaxial presence of salivary gland rests and concomitant Shh positivity of the described tumor point to a disorder in differentiation as opposed to ectopic developmental foci, which are uniformly dural based in the described literature. The authors demonstrate the characteristic "papilionaceous" appearance of the salivary glands with mucicarmine stain and highlight the role of Shh signaling in explaining the intraaxial presence of seromucous gland analogs. This article reports the first intraaxial posterior fossa tumor with heterotopic salivary gland rests, and it provides molecular and embryopathological insights into the development of these lesions.
\end{abstract}

http://thejns.org/doi/abs/10.3171/2016.6.PEDS15575

KEY WORDS ectopic salivary gland; medulloblastoma; sonic hedgehog; salivary gland rests; dissemination; differentiation; oncology

$\mathrm{H}$ ETEROTOPIC salivary gland tissue (HSGT) is composed of organized epithelial and mesenchymal components distant from the normal location of these tissues. HSGT is extremely rare and is most often found in the head and neck, including the middle ear, the external auditory canal, the thyroglossal duct, and the hard palate, as well as other extracranial regions, including the capsule of the thyroid and parathyroid glands. ${ }^{7,20}$ In the described literature, intracranial HSGT appears to be mostly confined to the posterior pituitary gland. Intracranial HSGT outside the sellar region has seldom been described (Table 1). The primary lesion in the subject of this report was a medulloblastoma positive for sonic hedgehog (Shh), an intraaxial posterior fossa neoplasm never reported to have intratumoral HSGT. The genetic characteristics of the tumor can plausibly serve as an explanation to the histological presence of mature salivary gland rests.

\section{Case Report}

A 12-year-old boy with no significant medical history presented with a 2-month history of progressive dizziness, gait ataxia, and intermittent nausea and vomiting. Physical examination showed right-sided dysmetria, ataxia, and markedly pronounced difficulty with tandem gait. The remainder of his examination was unremarkable. MRI of the brain revealed a $2.9 \times 2.7-\mathrm{cm}$ cystic ill-defined heterogeneously enhancing infiltrative mass lesion in the right cerebellar hemisphere extending into the cerebellar peduncle with effacement of the fourth ventricle and associated perilesional vasogenic edema. The mass extended into the right foramen of Luschka anterolaterally and into the foramen magnum posteromedially. Additional imaging abnormalities included areas of T2/FLAIR hyperintensity in the brainstem, cerebellar vermis, and contralateral cerebellar hemisphere. The clinical and radiological differential di- 
TABLE 1. Descriptions of intracranial HSGT outside the sellar region

\begin{tabular}{|c|c|c|c|c|}
\hline Authors \& Year & Age (yrs) & Location of HSGT & Type of Tissue & Intra-/Extraaxial \\
\hline \multicolumn{5}{|l|}{ Supratentorial } \\
\hline $\begin{array}{l}\text { Takahashi et al., } 2011 \\
\text { Chen et al., } 2007 \\
\text { van Furth et al., } 2007 \\
\text { Hwang et al., } 2007 \\
\text { Ranucci et al., } 2013 \\
\text { Chimelli et al., } 2000 \\
\text { Tatter et al., } 1995 \\
\text { Schochet et al., } 1974\end{array}$ & & Sella turcica & Salivary gland & Intraaxial \\
\hline Hintz et al., 2014 & 28 & Optic nerve sheath & Salivary choristoma & Extraaxial \\
\hline Erdogan et al., 2007 & 47 & Parafalcine-parasagittal dural based & Primary myoepithelial tumor & Extraaxial \\
\hline \multicolumn{5}{|l|}{ Infratentorial } \\
\hline Oh et al., 2013 & 56 & Cerebellomedullary cistern dural based & $\begin{array}{l}\text { Glioneuronal heterotopia w/ salivary gland rests \& } \\
\text { adipose tissue }\end{array}$ & Extraaxial \\
\hline Rodriguez et al., 2004 & 53 & Cerebellopontine angle dural based & Solitary fibrous tumor w/ salivary gland rests & Extraaxial \\
\hline Yano et al., 1997 & 35 & Posterior petrous dura & Pleomorphic adenoma & Extraaxial \\
\hline Morioka et al., 1993 & $65 / 61$ & Posterior fossa/middle fossa dural based & Adenoid cystic carcinoma & Extraaxial \\
\hline Curry et al., 1982 & 44 & Cerebellopontine angle dural based & Adenoid cystic carcinoma & Extraaxial \\
\hline
\end{tabular}

agnosis of ependymoma versus medulloblastoma was initially entertained.

The patient subsequently underwent a right retromastoid suboccipital craniectomy and near-total resection of the cerebellar tumor. Intraoperatively, the reddish-gray, moderately vascular tumor was noted to be involving the right cerebellar hemisphere and adjacent middle cerebellar peduncle with extensive adhesions of the exophytic component to the cranial nerves (CNs) V-X. A near-total resection was achieved and confirmed by postoperative imaging and demonstrated no areas of abnormal enhancement; however, areas of postoperative edema could have represented residual tumor. Initial MRI results of the complete neuraxis were negative for drop metastasis, but examination of lumbar CSF revealed malignant cells. Postoperatively, the patient reported improvement in his symptoms with a decrease in vomiting; however, he continued to have significant ataxia and was experiencing diplopia.

Histopathological examination revealed 2 distinct and discrete cell populations. The first population consisted of a high-grade primitive round blue cell tumor compatible with medulloblastoma (Fig. 1), while the second lineage consisted of ectopic mature salivary gland rests (Fig. 2). On immunostaining, the tumor cells were positive for CD56, and negative for GFAP, SALL-4, desmin, MSA, AFP, PLAP, CD117, beta HCG, chromogranin, and OCT4. The tumor cells retained INI-1 staining, which ruled out other small round blue cell tumors. The proliferative index of tumor cells indicated by Ki 67 was high. These morphological and immunophenotypical features were consistent with medulloblastoma.

Due to the presence of additional imaging abnormalities concerning for metastatic disease and the presence of malignant cells in CSF, the patient was diagnosed with high-risk medulloblastoma and was enrolled onto Children's Oncology Group study ACNS0332, regimen C, and treated with craniospinal radiotherapy and weekly vin- cristine chemotherapy, followed by maintenance chemotherapy with vincristine, cisplatin, cyclophosphamide, and retinoic acid. His course was complicated by loss of vision in the left eye, the development of pseudotumor cerebri, bilateral CN VI palsies, headaches, vomiting, failure to thrive, and severe deconditioning. Seven months after the initial diagnosis of medulloblastoma, while still receiving planned maintenance chemotherapy, the patient was found on routine surveillance imaging to harbor a new enhancing right parietooccipital mass. He underwent a craniotomy for an open biopsy and resection, which revealed cells of primitive neuroectodermal origin consistent with the primary tumor, albeit with no evidence of salivary gland rests. Given the progression of disease, he was taken off study and subsequently treated with temozolomide, irinotecan, and bevacizumab chemotherapy. During 5 months of this therapy, he continued to have clinical decline and ultimately was found to have progressive disease in the brainstem and posterior fossa as well as leptomeningeal dissemination in the spinal cord. Testing performed as part of the PBTC-032 (Pediatric Brain Tumor Consortium Trial 032) was consistent with medulloblastoma of the Shh molecular subgrouping. ${ }^{5,30} \mathrm{He}$ was enrolled onto PBTC032 and treated with vismodegib (GDC-0449), but he continued to experience rapid clinical deterioration and was taken off study after completing 1 cycle of treatment. He rapidly died of his disease just 15 months after initial diagnosis, and an autopsy performed at an outside institution revealed disseminated medulloblastoma with no evidence of salivary gland rests (Fig. 3).

\section{Discussion}

When present intracranially, HSGT is usually found within the posterior pituitary gland as incidental salivary gland rests. ${ }^{11}$ A postmortem histological study by Schochet and colleagues discovered salivary gland rests in $3.4 \%$ of 


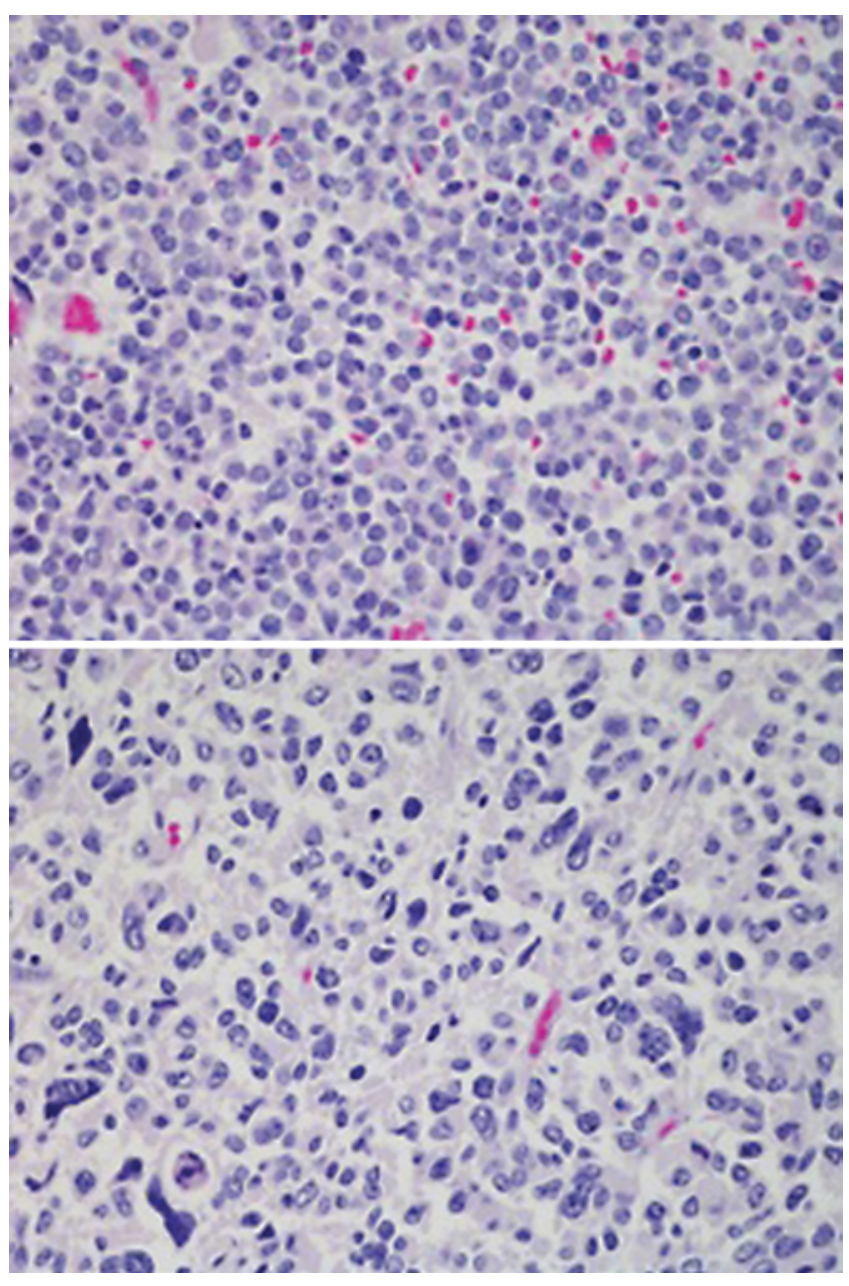

FIG. 1. Upper: There is a diffuse infiltrate of relative monomorphic medulloblastoma tumor cells in the cerebellum. The tumor cells have round nuclei, a salt-and-pepper nuclear chromatin pattern, and a scant amount of cytoplasm. The tumor cells are similar to the initial resection specimen before therapy. Lower: Some medulloblastoma cells are pleomorphic with nuclear enlargement, open chromatin, and occasional multinucleation. $H \& E$, original magnification $\times 40$. Figure is available in color online only.

2300 pituitaries. ${ }^{30}$ This not uncommon finding can be well explained by regional embryo-anatomical development. Both the anterior pituitary lobe and salivary glands, specifically the parotid gland, form from the ectoderm of the stomodeum, the primordial mouth. The anterior pituitary forms from the medial evagination, Rathke's pouch..$^{15}$ The anterior pituitary joins the neural ectoderm infundibulum that originates from the third ventricular floor, tissue that eventually becomes the posterior pituitary. ${ }^{2}$ Thus, the embryology of the pituitary can explain the findings of HSGT within the pituitary. Intraaxial salivary gland tissue outside the pituitary, however, has not been described and is not readily explained by the developmental sequence of salivary gland tissue. Extraaxial posterior fossa HSGT has been reported by Rodriguez et al. in the cerebellopontine angle. ${ }^{24}$ In this report, we describe the first case of mature salivary gland tissue found intraaxially in the posterior fossa.

The most pertinent question is whether the population

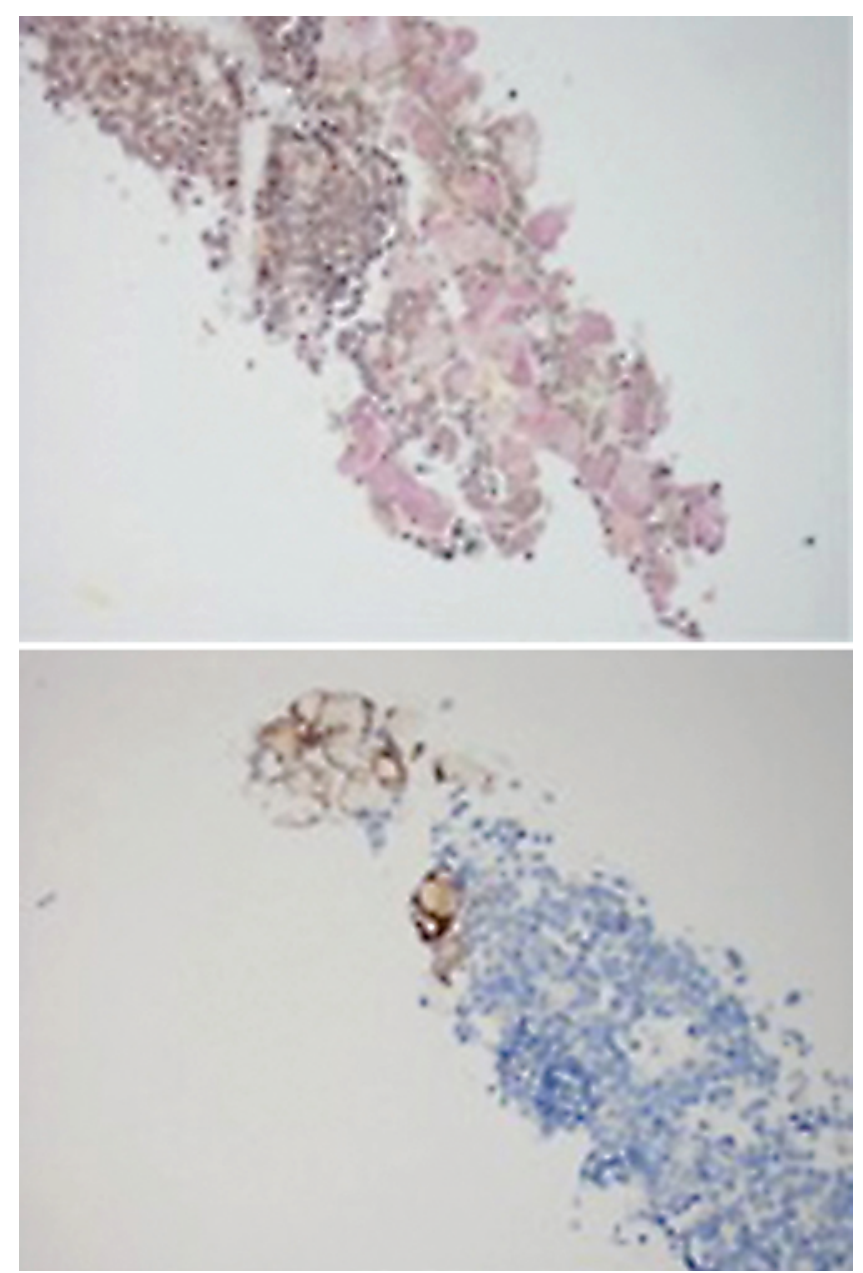

FIG. 2. Upper: Mucicarmine stain demonstrating the papilionaceous appearance of pink mucinous elements embedded within the population of small rounded cells of medulloblastoma. Lower: A CAM 5.2-stained section demonstrating epithelial differentiation. Original magnification $\times 100$. Figure is available in color online only.

of mature salivary gland rests was ectopic foci or differentiated pluripotent tumor cells. Medulloblastomas have been observed to contain cells of various differentiation from myogenic to melanocytic. Less common, but still documented, are medulloblastomas that contain organized tissue types. There are reports of these posterior fossa tumors with tissues displaying glandular features. ${ }^{18} \mathrm{Ng}$ and Poon described a medulloblastoma with acinar structures composed of cuboidal and low columnar cells with a luminal border. ${ }^{17}$ Medulloblastomas with multipotent differentiation displaying cells of neuronal, melanotic, astrocytic, and myoblastic differentiation have also been reported. ${ }^{29}$

Intraaxial salivary gland tissue within a medulloblastoma may be explained by the molecular characteristics of the patient's tumor. Sonic hedgehog (Shh) plays a vital role in craniofacial development and has specific effects on the morphogenesis of the submandibular salivary glands. ${ }^{12}$ In addition, the same cell membrane proteins and downstream factors are involved in both medulloblastomas and glandular developments. PTCH1 is a cell membrane receptor of Shh and tonic inhibitor of the transmembrane protein Smoothened (SMO), the activation of which leads 


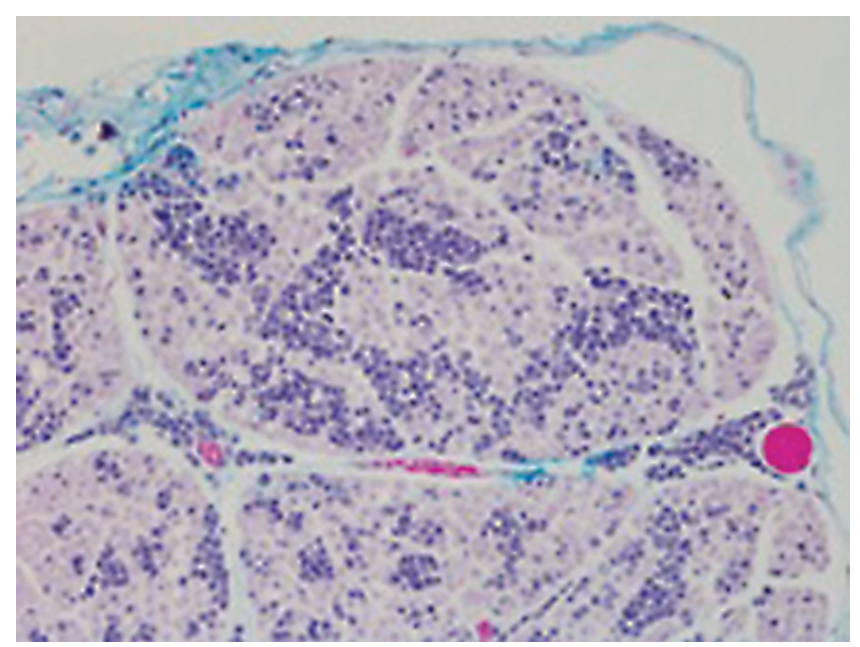

FIG. 3. Medulloblastoma cells infiltrating the spinal cord. There is a notable absence of salivary rests or cells with glandular characteristics. $\mathrm{H}$ $\& \mathrm{E}$, original magnification $\times 20$. Figure is available in color online only.

to eventual disinhibition of the Gli transcription factors. In the Shh molecular subtype of medulloblastomas, mutations of PTCH1 or downstream protein lead to tumor development through the uninhibited activation of the Shh pathway. ${ }^{4,32}$ Hedgehog stimulation serves as a potent proliferative signal for neural progenitor cells in the external granule layer (a proliferative region that produces over $90 \%$ of the neurons in the cerebellum) and medulloblastomas. While the Hedgehog pathway functions as a survival signal in the neural tube, it also regulates dorsoventral patterning by controlling neural progenitor cell apoptosis. Noguchi et al. used numerous Hedgehog antagonists (vismodegib, cyclopamine, and jervine) to show Hedgehog effects on apoptosis. ${ }^{18}$ The presence of Shh as an integral modulator of both salivary gland development and medulloblastoma progression would thus allow for a plausible explanation of the presence of mature salivary gland tissue in our patient. Thus, the common underlying molecular signature involving Shh may provide the reason why this tissue was intraaxial as opposed to dural based, as are the intracranial salivary gland rests previously reported in the literature. $3,6,10,16,22,25,31$

We did not have enough tissue specimen left for DNA extraction or studies on PTCH1 or SMO. When our patient developed acute disease progression after relapse, he was referred for a Pediatric Brain Tumor Consortium trial at Cincinnati Children's Hospital using an Shh targeted therapy (vismodegib). As part of that study, testing for this Pediatric Brain Tumor Consortium study was done at St. Jude's, and the patient was thought to have an Shh-subtype medulloblastoma. Vismodegib, originally approved by the US FDA on January 30, 2012, for the treatment of advanced basal cell carcinoma, showed promising results and then was used in malignancies, such as medulloblastoma, pancreatic cancer, multiple myeloma, chondrosarcoma, and prostate cancer. Similar Hedgehog inhibitors, such as LDE 225, saridegib, BMS 833923, LEQ 506, PF04449913, and TAK-441, are also under evaluation. Our article bridges the roles of Shh in development of organs and tissues during embryonic and postnatal periods, as well as the therapeutic role of Shh targeted therapy in solid tumors like medulloblastoma. ${ }^{9}, 14,18,21,23,26-28,32-33$ To validate the efficacy of vismodegib, 2 Phase II studies were performed in recurrent pediatric and adult medulloblastomas, which proved that vismodegib exhibits activity against adult recurrent Shh-medulloblastoma, but not against recurrent non-Shh medulloblastoma. Molecular analyses supported the hypothesis that SMO inhibitor activity depends on the genomic aberrations within medulloblastomas. ${ }^{21}$

Hintz and colleagues ${ }^{10}$ proposed another mechanism for the formation of HSGT in their case report of a 28-yearold woman with a salivary gland choristoma of the dural sheath of the optic nerve. They postulated that primitive submandibular glands form from neural crest cells, and dura mater (at least in mouse models) has been shown to contain embryologically significant pockets of these pluripotent cells. ${ }^{8,10,13}$ Consequently, these neural crest cells can differentiate into mature salivary gland tissue within the dura. Although adequate to explain the presence of mature salivary tissue in the previously described locations, it cannot fully explain the presence of intraaxial HSGT in our patient. We believe that our patient's HSGT is most consistent with a medulloblastoma with divergent differentiation forming mature salivary gland. At this time, it is uncertain whether HSGT could be a factor in the prognosis of patients with medulloblastoma, as there is no literature currently available to support HSGT as a prognostic marker. Similarly, TP53 mutations in Shh pathway-associated medulloblastomas seem to portend a very poor prognosis; however, only dedicated studies in this area can portend the actual role of HSGT and TP53 in the biological behavior of Shh-medulloblastomas.

\section{Conclusions}

The presence of mature salivary gland rests within medulloblastoma raises questions about the role of differentiation versus disorders of cell migration. The intraaxial presence of seroglandular tissue and Shh positivity of the described tumor provide a stronger argument of this tissue arising as a part of aberrant tumor cell differentiation than incidental trapped benign cellular nests. However, the absence of glandular elements within metastatic lesions could prove the contrary. More cases need to be studied in understanding the effect of these glandular ectopic tissues in natural history of the primary tumors.

\section{Acknowledgments}

We thank Fausto Rodriguez, MD, Department of Pathology at the Johns Hopkins University, for the invaluable input in verification of histopathological diagnosis.

\section{References}

1. Chen CH, Hsu SS, Lai PH, Lo YS: Intrasellar symptomatic salivary gland rest. J Chin Med Assoc 70:215-217, 2007

2. Chimelli L, Gadelha MR, Une K, Carlos S, Pereira PJ, Santos JL, et al: Intra-sellar salivary gland-like pleomorphic adenoma arising within the wall of a Rathke's cleft cyst. Pituitary 3:257-261, 2000

3. Curry B, Taylor CW, Fisher AW: Salivary gland heterotopia: a unique cerebellopontine angle tumor. Arch Pathol Lab Med 106:35-38, 1982 
4. DeSouza RM, Jones BR, Lowis SP, Kurian KM: Pediatric medulloblastoma-update on molecular classification driving targeted therapies. Front Oncol 4:176, 2014

5. Ellison DW, Dalton J, Kocak M, Nicholson SL, Fraga C, Neale G, et al: Medulloblastoma: clinicopathological correlates of SHH, WNT, and non-SHH/WNT molecular subgroups. Acta Neuropathol 121:381-396, 2011

6. Erdogan S, Rodriguez FJ, Scheithauer BW, Abell-Aleff PC, Rabin M: Malignant myoepithelioma of cranial dura. Am J Surg Pathol 31:807-811, 2007

7. Ferlito A, Bertino G, Rinaldo A, Mannarà GM, Devaney KO: A review of heterotopia and associated salivary gland neoplasms of the head and neck. J Laryngol Otol 113:299-303, 1999

8. Gagan JR, Tholpady SS, Ogle RC: Cellular dynamics and tissue interactions of the dura mater during head development. Birth Defects Res C Embryo Today 81:297-304, 2007

9. Gajjar A, Stewart CF, Ellison DW, Kaste S, Kun LE, Packer RJ, et al: Phase I study of vismodegib in children with recurrent or refractory medulloblastoma: a Pediatric Brain Tumor Consortium study. Clin Cancer Res 19:6305-6312, 2013

10. Hintz EB, Yeaney GA, Buchberger GK, Vates GE: Intracranial salivary gland choristoma within optic nerve dural sheath: case report and review of the literature. World Neurosurg 81:842.e1-842.e4, 2014

11. Hwang JH: Pituitary symptomatic salivary gland rest cyst: case report. Brain Tumor Res Treat 1:54-56, 2013

12. Jaskoll T, Leo T, Witcher D, Ormestad M, Astorga J, Bringas $\mathrm{P} \mathrm{Jr}$, et al: Sonic hedgehog signaling plays an essential role during embryonic salivary gland epithelial branching morphogenesis. Dev Dyn 229:722-732, 2004

13. Jaskoll T, Zhou YM, Chai Y, Makarenkova HP, Collinson JM, West JD, et al: Embryonic submandibular gland morphogenesis: stage-specific protein localization of FGFs, BMPs, Pax6 and Pax9 in normal mice and abnormal SMG phenotypes in FgfR2-IIIc(+/Delta), BMP7(-/-) and Pax6(-/) mice. Cells Tissues Organs 170:83-98, 2002

14. Metcalfe C, Alicke B, Crow A, Lamoureux M, Dijkgraaf GJ, Peale F, et al: PTEN loss mitigates the response of medulloblastoma to Hedgehog pathway inhibition. Cancer Res 73:7034-7042, 2013

15. Moore KL, Persaud TVN, Torchia MG: The Developing Human: Clinically Oriented Embryology, ed 9. Philadelphia: Saunders/Elsevier, 2013

16. Morioka T, Matsushima T, Ikezaki K, Nagata S, Ohta M, Hasuo K, et al: Intracranial adenoid cystic carcinoma mimicking meningioma: report of two cases. Neuroradiology 35:462-465, 1993

17. Ng HK, Poon WS: Adenoid formation in medulloblastoma: a case report. Surg Neurol 42:400-407, 1994

18. Noguchi KK, Cabrera OH, Swiney BS, Salinas-Contreras P, Smith JK, Farber NB: Hedgehog regulates cerebellar progenitor cell and medulloblastoma apoptosis. Neurobiol Dis 83:35-43, 2015

19. Oh SJ, Lee D, Suh YL, Lee JI: Heterotopic glioneuronal mass of the cerebellomedullary cistern with duct cyst formation of ectopic salivary gland tissue. Neuropathology 33:179-184, 2013

20. Peters BR, Maddox HE III, Batsakia JG: Pleomorphic adenoma of the middle ear and mastoid with posterior fossa extension. Arch Otolaryngol Head Neck Surg 114:676-678, 1988

21. Ranucci V, Coli A, Marrucci E, Paolo MP, Della Pepa G, Anile C, et al: Ectopic salivary gland tissue in a Rathke's cleft cyst. Int J Clin Exp Pathol 6:1437-1440, 2013

22. Rimkus TK, Carpenter RL, Qasem S, Chan M, Lo HW: Targeting the Sonic Hedgehog signaling pathway: review of smoothened and GLI inhibitors. Cancers (Basel) 8:E22, 2016
23. Robinson GW, Orr BA, Wu G, Gururangan S, Lin T, Qaddoumi I, et al: Vismodegib exerts targeted efficacy against recurrent Sonic Hedgehog-subgroup medulloblastoma: results from Phase II Pediatric Brain Tumor Consortium studies PBTC-025B and PBTC-032. J Clin Oncol 33:26462654, 2015

24. Rodriguez F, Scheithauer BW, Ockner DM, Giannini C: Solitary fibrous tumor of the cerebellopontine angle with salivary gland heterotopia: a unique presentation. Am J Surg Pathol 28:139-142, 2004

25. Rudin CM, Hann CL, Laterra J, Yauch RL, Callahan CA, Fu L, et al: Treatment of medulloblastoma with hedgehog pathway inhibitor GDC-0449. N Engl J Med 361:1173-1178, 2009

26. Sakata H, Kanamori M, Watanabe M, Kumabe T, Tominaga T: Medulloblastoma demonstrating multipotent differentiation: case report. Brain Tumor Pathol 25:39-43, 2008

27. Samkari A, White J, Packer R: SHH inhibitors for the treatment of medulloblastoma. Expert Rev Neurother 15:763770,2015

28. Sandhiya S, Melvin G, Kumar SS, Dkhar SA: The dawn of hedgehog inhibitors: Vismodegib. J Pharmacol Pharmacother 4:4-7, 2013

29. Schmidt C: Targeted therapy makes inroads in medulloblastoma. J Natl Cancer Inst 107:djv353, 2015

30. Schochet SS Jr, McCormick WF, Halmi NS: Salivary gland rests in the human pituitary. Light and electron microscopical study. Arch Pathol 98:193-200, 1974

31. Takahashi S, Mikami S, Akiyama T, Kawase T: Intrasellar salivary gland-like pleomorphic adenoma: case report. Neurosurgery 68:E562-E566, 2011

32. Tatter SB, Edgar MA, Klibanski A, Swearingen B: Symptomatic salivary-rest cyst of the sella turcica. Acta Neurochir (Wien) 135:150-153, 1995

33. Taylor MD, Northcott PA, Korshunov A, Remke M, Cho YJ, Clifford SC, et al: Molecular subgroups of medulloblastoma: the current consensus. Acta Neuropathol 123:465-472, 2012

34. van Furth W, Smyth HS, Horvath E, Kovacs K, Salehi F, Cusimano MD: Salivary gland-like tumor of the sella. Can J Neurol Sci 34:478-482, 2007

35. Yano H, Funakoshi T, Shinoda J, Sakai N, Kokuzawa G, Shimokawa K: Primary pleomorphic adenoma in posterior cranial fossa. Brain Tumor Pathol 14:75-78, 1997

\section{Disclosures}

The authors report no conflict of interest concerning the materials or methods used in this study or the findings specified in this paper.

\section{Author Contributions}

Conception and design: Shammassian, Manjila. Acquisition of data: Shammassian, Cox, Wang. Analysis and interpretation of data: Shammassian, Manjila, Cox, Onwuzulike, Wang, Stearns. Drafting the article: Shammassian, Manjila, Cox, Onwuzulike. Critically revising the article: Selman, Shammassian, Cox, Onwuzulike, Rodgers, Stearns. Reviewed submitted version of manuscript: Shammassian. Approved the final version of the manuscript on behalf of all authors: Selman. Administrative/technical/material support: Shammassian.

\section{Correspondence}

Warren R. Selman, Department of Neurological Surgery, University Hospitals Case Medical Center, 11100 Euclid Ave., Cleveland, OH 44106. email: warren.selman@uhhospitals.org. 